\title{
Results in 50 cases of strabismus after graduated surgery designed by A scan ultrasonography
}

\author{
W. E. GILliES and ANNE HUGHES \\ From the Royal Victorian Eye and Ear Hospital, and the School of Orthoptics, Lincoln Institute, \\ Melbourne, Australia
}

SUMmARY Of 50 cases of strabismus having surgical operations designed on the basis of A scan ultrasonography $45(90 \%)$ had less than 10 dioptres eso- or exodeviation two months postoperatively; 22 eso-, 25 exo-, and 3 vertical deviations were included in the series. A scan ultrasonography is done preoperatively to find the diameter and thus the circumference of the globe. This is used with the angle of deviation to estimate the amount of recession and/or resection necessary to correct the deviation. Attention is drawn to the oculomotor axis, which is $10-12^{\circ}$ divergent to the anteroposterior axis and around which the recti muscles act. The oculomotor equator is at right angles to this axis and is closer to the limbus medially than laterally, so that excessive recession of the medial rectus is more likely than of the lateral rectus.

We have previously described a method using the ocular dimensions as determined by A scan ultrasonography to design the squint operation. ${ }^{1-3}$ Measurements of ocular dimensions in normal eyes show considerable variation as found by Sorsby and others ${ }^{4}$ and Stenstrom, ${ }^{5}$ though emmetropic and hypermetropic eyes are essentially spherical. We believe that by allowing for this variation preoperative measurement of the ocular dimensions of squinting patients permits greater precision and predictability in the execution of squint surgery.

The present paper describes the results of surgical operation in 50 cases of squint of different kinds in which the method was used.

\section{Material and method}

The 50 consecutive cases comprised 22 with esodeviations, 9 with and 13 without a significant vertical component; 25 with exodeviations, 5 with and 20 without a significant vertical component; and 3 purely vertical deviations. Using A scan ultrasonography we made several measurements before operation in addition to the usual estimations of angle of deviation and ocular movements.

(1) The diameter of the eye is measured in an anteroposterior (AP) direction. From this the cir-

Correspondence to Dr W. E. Gillies, 110 Collins Street, Melbourne, Victoria 3000, Australia. cumference of the eye is estimated $(2 \pi r)$ and then the length of a quadrant from the central cornea to the equator of the eye (one-quarter of circumference) (Fig. 1).

(2) The length of the oculomotor axis, which runs from the front of the eye through the centre of the eye to the apex of the orbit, whence the recti muscles originate, is measured. It is around this oculomotor axis that the recti muscles act, and this axis is divergent to the AP axis (Fig. 2). The oculomotor equator is at right angles to this axis and is about $2 \mathrm{~mm}$ closer to the limbus than the transverse equator on the medial side but $2 \mathrm{~mm}$ further on the lateral side (Fig. 3 ).

(3) The oculmotor angle, which is the angle between the oculomotor axis and the AP axis (the oculomotor axis being $10^{\circ}-12^{\circ}$ divergent to the latter) is measured. The size of this angle determines the position of the oculomotor equator of the eye (Fig. 3). Measurement of nos 2 and 3 is more difficult than no 1 . As the diameter of the eye is more variable than the other two measurements, surgery may be designed on the basis of the AP diameter alone in the majority of patients, particularly as most surgery does not approach the limits where muscle length becomes important and the oculomotor angle does not vary much.

In small children measurement of the diameter of the eye had to be performed under anaesthetic immediately before operation, and it was not possible to measure the oculomotor axis. 


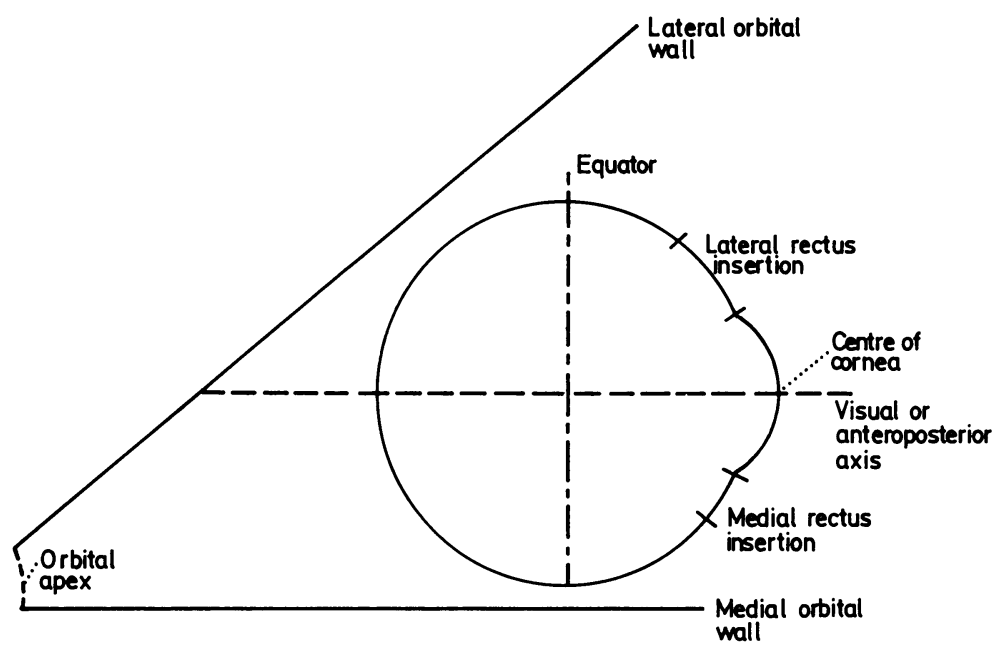

Fig. 1 Relationship of the anteroposterior axis, the geometric equator of the eye, and the recti muscle insertions to a quadrant of the circumference from central cornea to the equator.

At operation two more measurements are made: (1) the corneal diameter, (2) the distance of the rectus muscle insertion from the limbus. The amount of recession to be performed is calculated from the simple formula:

Effective recession $=\frac{\text { Angle of squint }}{360^{\circ}} \times$ circumference of eye.

An amount of $1.5-2 \mathrm{~mm}$ is added to this to allow for loss of effectivity in cutting and suturing the muscle.

About half the effect of this recession will be lost because of slackness of the antagonist muscle unless a corresponding shortening of the antagonist is performed. ${ }^{\circ}$ An addition of $2-4 \mathrm{~mm}$ is allowed with resection to allow for slippage and for the stretching of the muscle when measurements are taken.

We consider it undesirable to recess a muscle beyond the oculomotor equator, as this will result in some weakness of action of the muscle in its field of action. This will be more marked the further the muscle is recessed. With a large angle of deviation it may be worth 'trading off' some weakness of action for straight visual axes in the primary position.

The correction for the oculomotor angle is derived from the formula:

$$
\frac{\text { Oculomotor angle (degrees) }}{360^{\circ}} \times \text { circumference }
$$

It is usually about $2 \mathrm{~mm}$, and this figure may be used to estimate the position of the oculomotor equator, which may be considered the limit of a 'safe' recession.

'Safe' medial rectus recess $=$ Quadrant $-2-(1 / 2$ corncal diameter + distance of insertion from limbus).

'Safe' lateral rectus recess $=$ Quadrant $+2-(1 / 2$ corneal diameter + distance of insertion from limbus).

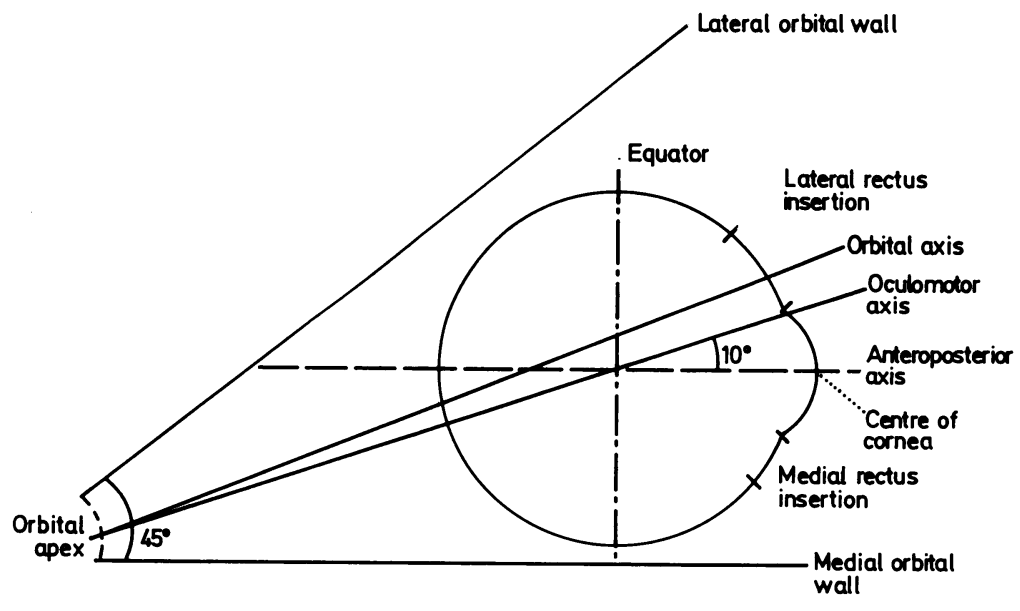

Fig. 2 Relationship of the oculomotor axis to the anteroposterior axis and the orbital axis. 
Fig. 3 Relationship of the oculomotor equator to the equator, and the recti muscle insertions. oculomotor axis, the transverse

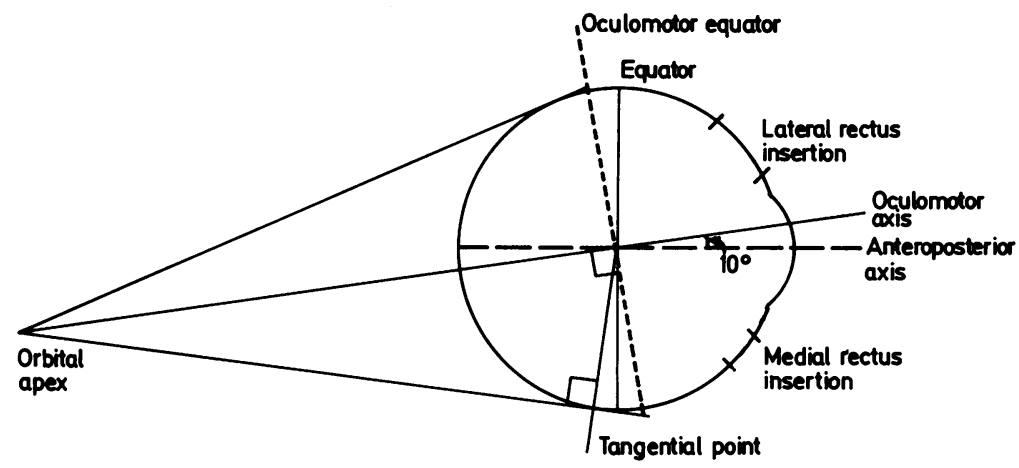

The amount of resection of the antagonist corresponds to the amount of recession +2 or $4 \mathrm{~mm}$ as described above. For large angles larger resections may be done to increase the effect of operation, but we prefer not to exceed $0 \cdot 25$ of muscle length for the medial rectus and $\mathbf{0 . 3 0}$ for the lateral rectus having regard to the heavier structure of the medial rectus. For recession a weakness of action may result if the new insertion of the muscle is brought too close to its origin.

Horizontal rectus muscles were recessed or resected in their line of action and not moved vertically, as we felt vertical movement of horizontal recti would have an unpredictable effect on their horizontal action. When a V or A pattern needed correction, this was achieved by operation on the appropriate oblique muscles, usually by recession.

Oblique muscles were also operated on when a significant vertical error accompanied a horizontal deviation. Boeder ${ }^{7}$ considered that in the straight ahead position the inferior oblique muscle contributed about $30 \%$ of the force of elevation, while the superior rectus contributed about $60 \%$. He considered that the superior oblique muscle contributed a lesser moiety of depression. However, Gillies ${ }^{89}$ found that similar amounts of recession of the inferior and superior oblique muscles gave similar angular correction. Further, Jampel ${ }^{10}$ believes that the vertical rectus and oblique muscles in man work together to give vertical ocular movements.

Therefore, somewhat empirically, we have assumed that an oblique muscle supplies about onethird of a vertical eye movement, and the amount of effective recession or resection calculated from the angle of deviation must be multiplied by 3 , and if only one oblique muscle is operated upon this must be multiplied again by 2 , that is, the amount of recession calculated for an oblique muscle to correct a certain angle must be multiplied by 6 to arrive at the effective recession, if only one oblique muscle is to be operated upon.

Sometimes vertical recti muscles were operated upon in order to correct vertical angles. As these muscles supply about two-thirds of a vertical movement the amount of recession or resection calculated from the angle of deviation and the circumference of the eye must be multiplied by $3 / 2$ and by a further 2 times if only one vertical rectus is operated upon.

\section{ORDER OF ACCURACY}

The diameter of the globe seems an accurate measurement on the A scan and is highly reproducible. It is made from the front of the cornea to the front of the retina, and a correction of $+1 \mathrm{~mm}$ may be made to estimate the position of the posterior surface of the sclera. Measurement of the oculomotor axis is reproducible only to $\pm 2 \mathrm{~mm}$, as the apex of the orbit is not a point but an area of muscle origin. The oculomotor angle is accurate to $2^{\circ}$ to $3^{\circ}$. Measurements made on the surface of the globe at operation are 'chord' measurements and are not strictly circumferential, introducing a small error. This is less than $0.5 \mathrm{~mm}$ for a corneal diameter of $12 \mathrm{~mm}$ in an eye of $24 \mathrm{~mm}$ diameter. It is assumed that the centre of rotation of the eye coincides with the geometric centre of the eye, which may not be true, but as the centre of rotation may change with different positions of the eye it is almost impossible to measure it precisely. It is also assumed that the eye is spherical ${ }^{41}$ which is accepted as very nearly true for emmetropic and hypermetropic eyes, and for myopia up to $-4 \mathrm{OD}$, but highly myopic eyes are more elliptical. There was only one myopic eye in this series. Even with these approximations we feel measurement by A scan gives much greater accuracy in squint surgery than methods currently in use.

\section{Results}

The postoperative assessment of the result was done two to three months after operation, when the position of the eyes and the effect of operation were reasonably stable. In 13 cases of esodeviation with no significant vertical deviation and a preoperative angle 
Table 1 Results of surgery esodeviations

\begin{tabular}{lrll}
\hline & & $\begin{array}{l}\text { Less than } 10^{\Delta} \text { eso } \\
\text { or } 10^{\Delta} \text { exo }\end{array}$ & $10-15^{\Delta}$ eso \\
\hline No vertical component & 13 & 12 & 1 \\
With vertical component & 9 & 7 & 2 \\
Total & 22 & 19 & 3 \\
\hline
\end{tabular}

of 12 to 50 dioptres (average 37 dioptres) surgery resulted in a deviation of less than 10 dioptres in 12 patients, the other having a deviation of 12 dioptres eso. There were no overcorrections (Table 1).

The average anteroposterior (AP) diameter for this group was $23.08 \mathrm{~mm}$, range 20.05 to $26.72 \mathrm{~mm}$, standard deviation (SD) 1.41. The AP diameters of the undercorrected patient did not differ significantly from the group average, being 23.68 and $23.60 \mathrm{~mm}$.

\section{CASE REPORT}

A 1-year-old girl with a congenital right esodeviation of 45 dioptres (alternating after occlusion) after measurement with A scan showed: Diameter of right eye $21.5 \mathrm{~mm}$, left eye $20.5 \mathrm{~mm}$; circumference of right eye $67.5 \mathrm{~mm}$; quadrant $16.89 \mathrm{~mm}$. Measurement at operation was: corneal diameter $11 \mathrm{~mm}$, medial rectus $4.0 \mathrm{~mm}$ from limbus; lateral rectus $5.0 \mathrm{~mm}$ from limbus.

$$
\text { Recession needed: } \frac{45 \times 67.57}{720^{\circ}}=4.2 \mathrm{~mm}+1 \cdot 5-2 \cdot 0 \mathrm{~mm} \text {. }
$$

This approximately equals $6 \cdot 0 \mathrm{~mm}$.

Safe recession $=16 \cdot 89 \mathrm{~mm}-2-(5 \cdot 5+4 \cdot 0)=5 \cdot 39$ $\mathrm{mm}$.

Operation done: right medial rectus recession 6 $\mathrm{mm}$; right lateral rectus resection $8 \mathrm{~mm}$.

Results postoperatively at three months: straight by corneal, reflections and cover test, slight right medial rectus weakness.

Comment: A large recession just outside 'safe' limits secured straight visual axes with slight medial rectus weakness.

Of a group of nine patients with esodeviation who were also operated upon for a vertical component six achieved less than 10 dioptres esodeviation and one four dioptres exodeviation. Of the other two one had 12 dioptres esodeviation for distance and 18 dioptres for near, the other 14 dioptres esodeviation. The preoperative esodeviation in this group varied from 20 dioptres to 50 dioptres (average 33.3 dioptres).

The average AP diameter for this group was 23.08 $\mathrm{mm}$, range $21.4-24.85 \mathrm{~mm}$, SD 0.92 . The AP diameters of the undercorrected cases were 23.23 and $22.85 \mathrm{~mm}$ for one and 24.12 and $23.34 \mathrm{~mm}$ for the other.

Nineteen patients with exodeviations had operations on horizontal recti only, five having bilateral
Table 2 Results of surgery exodeviations

\begin{tabular}{|c|c|c|c|c|c|}
\hline & & & $\begin{array}{l}\text { Less than } \\
10^{\Delta} \text { exo }\end{array}$ & $\begin{array}{l}10-15^{\Delta} \\
\text { exo }\end{array}$ & $\begin{array}{l}10-15^{\Delta} \\
\text { eso }\end{array}$ \\
\hline \multirow[t]{2}{*}{$\begin{array}{l}\text { No vertical } \\
\text { component }\end{array}$} & 19 & $\begin{array}{l}\text { Bilateral } \\
\text { recession }\end{array}$ & 5 & 0 & \\
\hline & & $\begin{array}{l}\text { Recession } \\
\text { resection }\end{array}$ & 13 & 0 & 1 \\
\hline $\begin{array}{l}\text { With vertical } \\
\text { component }\end{array}$ & 6 & & 5 & 1 & \\
\hline Total & 25 & & 23 & 1 & 1 \\
\hline
\end{tabular}

lateral rectus recessions and 14 lateral rectus recessions with medial rectus resection. Many of this latter group were amblyopic or had consecutive exodeviations.

The five cases having bilateral lateral rectus recessions had preoperative exodeviations ranging from 25 dioptres to 45 dioptres (average 36 dioptres) and all achieved an exodeviation less than 10 dioptres with no tropia (Table 2). The average AP diameter for this group was $22.98 \mathrm{~mm}$ range $21.0-24.93 \mathrm{~mm}$, SD $1.31 \mathrm{~mm}$.

The 14 cases having lateral rectus recession with medial rectus resection had preoperative exodeviations ranging from 25 to 55 (average 39.5 dioptres), and 13 achieved deviations less than 10 dioptres, while one had an esodeviation of 14 dioptres with an amblyopic eye. The average AP diameter for this group was 23.22 , range $21-25.74 \mathrm{~mm}$, SD $1.15 \mathrm{~mm}$. The overcorrected case had an AP diameter of 23.02 and $22.54 \mathrm{~mm}$.

Six patients had an operation for an exodeviation combined with surgery for a vertical component, five of these achieving an exodeviation less than 10 dioptres with correction of the vertical component, while one had a residual exodeviation of 12 dioptres. Preoperative deviation varied from eight dioptres to 40 dioptres in this group (average 21.3 dioptres). The average AP diameter for this group was $24.13 \mathrm{~mm}$, range $21.4-27.28 \mathrm{~mm}$, SD $1.67 \mathrm{~mm}$. The patient who was undercorrected had an AP diameter of 23.74 and $23.54 \mathrm{~mm}$.

\section{CASE REPORT}

A 4-year-old boy had exodeviation with A pattern. Primary position was 15 dioptres exodeviation, full elevation was straight, and depression was 25 dioptres exodeviation. Measurement with A scan showed diameter of the right eye $23.67 \mathrm{~mm}$ and that of the left eye $23.5 \mathrm{~mm}$. Circumference of the right eye was $74.39 \mathrm{~mm}$ and the left eye, $73.86 \mathrm{~mm}$. Quadrant of right eye was $18.6 \mathrm{~mm}$ and left eye, $18.46 \mathrm{~mm}$. Measurement at operation was cornea $12 \mathrm{~mm}$ and lateral rectus $6 \mathrm{~mm}$ from limbus.

$$
\text { Recession needed: } \frac{15}{720} \times \frac{74.39 \mathrm{~mm}}{1}=1.55 \mathrm{~mm} \text {. }
$$


If only one muscle was operated on the recession needed would have been $1.5 \mathrm{~mm} \times 2+2=5.1 \mathrm{~mm}$. 'Safe' recession would have been $18.6 \mathrm{~mm}+2-(6+6)$ $=8.6 \mathrm{~mm}$.

Operation done: recess right lateral rectus $7 \mathrm{~mm}$, recess right and left superior oblique $8 \mathrm{~mm}$. Postoperative 2/12: small esodeviation 4 dioptres No 'A'.

Comment: In view of the unpredictability of single muscle recessions and the desirability of a small overcorrection of an exodeviation an extra $2 \mathrm{~mm}$ of lateral rectus recession was performed, resulting in a small overcorrection.

Three cases with a vertical deviation which ranged from 10 dioptres to 25 dioptres were operated on vertical or oblique muscles only, either eliminating the vertical deviation or reducing it to four dioptres. The average AP diameter was $23.79 \mathrm{~mm}$, range 22.87 to $24 \cdot 83$, SD $0.65 \mathrm{~mm}$.

\section{CASE REPORT}

A 58-year-old woman had thyrotrophic disease with marked limitation of elevation of her left eye. Primary position $R / L$ was 20 dioptres.

Measurements with A scan showed the diameter of the right eye to be $23.76 \mathrm{~mm}$ and left eye $23.53 \mathrm{~mm}$; the circumference of the left eye was $73.95 \mathrm{~mm}$ and the quadrant $18.49 \mathrm{~mm}$. The measurement at operation was cornea $11.5 \mathrm{~mm}$, inferior rectus $6.0 \mathrm{~mm}$.

Inferior rectus effective recession needed: if only one muscle done

$$
=\frac{20}{720} \times \frac{73.95 \mathrm{~mm}}{1} \times \frac{3}{2} \times 2=6 \cdot 15 \mathrm{~mm} .
$$

Add $+1.5 \mathrm{~mm}$ approximatcly equals $7.5 \mathrm{~mm}$.

Operation done: Left recession inferior rectus $7 \cdot 5$ $\mathrm{mm}$.

Postoperative: Straight in primary position with small limitations of elevation and depression.

Comment: a large recession of the inferior rectus has secured alignment of the eyes in the primary position with satisfactory excursion of the eye.

The group of case is very heterogeneous, and there are reservations about conclusions for the group as a whole. However, if reduction of the horizontal deviation to less than 10 dioptres and the vertical deviation to less than five dioptres is an excellent result, then 45 cases $(90 \%)$ achieved such a result. The average AP diameter for the whole group of 50 cases was $23.28 \mathrm{~mm}$, range 20.05 to $27.28 \mathrm{~mm}$, SD $1.28 \mathrm{~mm}$. The five cases with poor results did not differ significantly from the average. Three of the poor results occurred in cases also operated upon for vertical error, and such cases are more difficult to predict, especially when there is still some lack of experience in using a new method. One other poor result was a small undercorrection of an esodeviation. Another was a small, cosmetically satisfactory overcorrection of a large exodeviation in an amblyopic eye.

\section{Discussion}

The results we have obtained in squint surgery using the method described compare favourably with our own ${ }^{12-14}$ and other ${ }^{15-21}$ results by standard operations with some variation in the amount of surgery for the degree of angle of deviation. We believe the use of $A$ scan is the basis of a simple, effective method, which allows a graduated amount of extraocular muscle surgery appropriate to a particular ocular deviation. With greater experience further refinement of the technique is likely. Surgical judgment remains as important as before in choosing a slight under- or overcorrection, allowing for the influence of binocular function and amblyopia, dealing with muscle underor overactions, or 'trading off' a small muscle underaction for straight visual axes in the primary position.

Attention is drawn to the concept of an oculomotor axis which is $10-15^{\circ}$ divergent to the anteroposterior axis and is the axis about which the recti muscles act. The oculomotor equator is at right angles to this axis and may be regarded as the limit of a completely 'safe' recession, though recession behind this will not result in weakness of muscle action in the primary position. Weakness in the primary position will occur only if the muscle is recessed beyond the tangential point, where the line of action of the muscle is tangential to the globe. This point lies about $5 \mathrm{~mm}$ behind the oculomotor equator and represents a rotation of $20-25^{\circ}$ before any mechanical disadvantage occurs if the muscle is placed at the oculomotor equator. When this point is passed there is a progressive loss of mechanical advantage with further rotation of the eye.

The weakening effect of moving the new insertion of a recessed muscle too close to its origin has been stressed by Beisner, ${ }^{22}$ who considered this a more important factor in producing muscle underaction than loss of mechanical advantage. We prefer to avoid recessions greater than $0.2 \mathrm{~mm}$ of muscle length, though usually this is likely to occur only with the lateral rectus, where larger recessions are possible as realised by Urist, ${ }^{23}$ the oculomotor equator being much further from the limbus on the lateral side. The much larger recessions of lateral rectus than medial rectus do not seem to be associated with a greater incidence of muscle underaction of the lateral rectus, though there is much more muscle shortening, suggesting that muscle shortening is not as important a reason as loss of mechanical advantage in causing muscle underaction after squint surgery. Excessive 
tightening of a muscle by resection is also undesirable, and we have preferred not to exceed 0.25 resection for a medial or 0.30 for a lateral rectus. These figures are still empirical.

Our figures confirmed the considerable variation in ocular diameter of eyes falling in the normal range of refractive error and also emphasised a variation in the site of the medial and lateral rectus muscle insertions, which should be allowed for in designing squint surgery. The method is essentially simple and the calculations based on elementary geometry. A pocket calculator will suffice to perform them and is a useful adjunct for strabismologists.

This work was carricd out under research project 38 of the Royal Victoria Eye and Ear Hospital and with the help of the Research and Higher Degrees Committee of Lincoln Institute for the Provision of Ultrasonography Equipment.

Our thanks are duc to Miss J. Quilter for assistance with references and Miss C. Atkinson for secretarial assistance.

\section{References}

1 Gillies WE, McIndoe A. Measurement of strabismus eyes with A scan. Aust J Ophthalmol 1981; 9: 231-2.

2 Gillies WE. McIndoe A. The use of ultrasonography in determining the amount of extraocular muscle surgery in strabismus. Aust J Ophthalmol 1982; 10: 191-4.

3 Gillies WE, McIndoe A. The use of a scan ultrasonography to design the squint operation. Proceedings of the International Strabismological Association and American Association of Pediatric Ophthalmology and Strabismus, Asilomar, 1982. In press.

4 Sorsby A, Benjamin B, Davey JB, Sheridan M, Tanner JM. Emmetropia and its aberrations. Medical Research Council special report series, No 293. London: HMSO 1957.
5 Stenstrom S. Untersuchungen über die Variation und Kovariation der optischen Elemente des menschlichen Auges. Acta Ophthalmol (Kbh) 1948; 26 (suppl): 5-103.

6 Dukc-Elder S, Wybar KC. Ocular motility and strabismus. In: System of ophthalmology. London: Kimpton, 1973: 503-5.

7 Boeder P. The co-operation of extraocular muscles. Am J Ophthalmol 1961; 51: 469-81.

8 Gillies WE. Recession of the inferior oblique. Trans Aust Coll Ophthalmol and Ophthalmol Soc NZ 1969-70; i-xxii: 101-5.

9 Gillies WE. Results with graduated recession of the superior oblique muscle. Aust J Ophthalmol 1980; 8: 11-4.

$10 \mathrm{Jampel}$ RS. Ocular torsion and the function of the vertical extraocular muscles. Am J Ophthalmol 1975; 79: 292-304.

11 Duke-Elder S. Wybar KC. The anatomy of the visual system. In System of ophthalmology. London: H Kimpton, 1961; 2: 78-81.

12 Gillies WE. The results of surgical treatment of esotropia. Aust J Ophthalmol 1974; 2: 20-3.

13 Gillies WE. Esotropia: the second operation. In: Moore S, Mein J, Stockbridge L, eds. Orthoptics past present and future. New York: Stratton Intercontinental, 1976: 443-8.

14 Gillies WE. The results of treatment of intermittent exodeviation. Trans Aust Coll Ophthalmol 1970); 2: 101-4.

15 Wheeler MC. Long term results of surgical treatment of strabismus. J Pediatr Ophthalmol 1972; 9: 76-8.

16 Edwards WC. Moran CT. Statistical analysis of esotropia surgery. J Pediatr Ophthalmol 1973; 10: 256-65.

17 Edwards WC, Moran CT. Statistical analysis of esotropia surgery. J Pediatr Ophthalmol 1974; 11: 177-83.

18 Hardesty HH, Boynton JR, Keenan JP. Treatment of intermittent exotropia. Arch Ophthalmol 1978; 96: 268-74.

19 Pratt-Johnson JA. Barlow JM. Tillson G. Early surgery in intermittent exotropia. Am J Ophthalmol 1977; 84: 689-94.

20 Scott WE, Keech R, Mash AJ. The postoperative results and stability of exodeviations. Arch Ophthalmol 1981; 99: 1814-8.

21 Clarke WN, Noel LP. Surgical results of intermittent exotropia Can J Ophthalmol 1981; 16: 66-9.

22 Beisner DH. Reduction of ocular torque by medial rectus recession. Arch Ophthalmol 1971; 85: 13-7.

23 Urist MJ. Exotropia with bilateral clevation in adduction. A m J Ophthalmol 1954; 38: 178-90. 


\section{Obituary}

\section{Manuel Lederman $M B, B S, F F R$, DMRE}

Manuel Lederman, who died on 27 June 1984, was born in 1911 and received his medical training at the Westminster Hospital, where he won the Sturges Prize for clinical medicine and the Hanbury Prize for diseases of children. He qualified in 1935 . His interest in radiotherapy was stimulated by Sir Stanford Cade, and his first appointment was that of resident medical officer to the Radium Annexe of the Westminster Hospital. Two years later he was appointed assistant radium therapist at the Royal Cancer Hospital (subsequently the Royal Marsden Hospital), where he spent the remainder of his career. His initial interests were gynaecological cancer and more especially head and neck cancer. He developed new techniques of irradiation of tumours of the head and neck using the newly installed teleradium units.

Early in his career Dr Lederman developed an interest in the treatment of diseases of the eye and orbit by ionising radiation. He took charge of the $x$-ray Department of Moorfields Eye Hospital in 1941, remaining in charge until 1948, when all radiotherapy was transferred from Moorfields to the Royal Cancer Hospital. He remained as honorary consultant radiotherapist to Moorfields Hospital and established a flourishing joint eye tumour clinic at both hospitals. He pioneered many techniques of radiotherapy of eye conditions, including the strontium-90 plaque for superficial irradiation of the cornea and conjunctiva, introduced in 1954. He had a special interest in the conservative treatment of epibulbar melanoma; his final paper describing his experience of the treatment of these tumours over a period of 31 years appeared posthumously in the British Journal of Ophthalmology last year.

He always emphasised the art rather than the science of radiotherapy. Nevertheless he had an unrivalled knowledge of the anatomy and physiology of the head and neck, which he applied to understanding the origin and spread of malignant tumours, enabling him to tailor radiotherapy technique to the individual patient without the aid of the more sophisticated imaging and technology now available. He was a fine teacher. As he saw each patient in his clinic he would expound articulately and succinctly on the natural history of the disease before him and on the rationale of the treatment in use, usually to an audience comprising not only his own juniors and students but also visiting doctors from many parts of the world. $\mathrm{He}$ was in great demand as a lecturer and contributor to scientific meetings. His presentations were invariably carefully prepared, well rehearsed, and fluently delivered. In discussion at meetings he could be a potent adversary, quick to spot the flawed argument or the unsubstantiated claim. He rapidly built up a reputation as a clinician which attracted patients from many countries. After his retirement from hospital practice in 1977 his advice continued to be sought by colleagues and patients, and he remained in active practice until a few weeks before his death.

His talents brought him many honours in the field of radiotherapy and oncology. The British Institute of Radiology awarded him the Roentgen Award in 1956 and the Barclay Medal in 1972 for his contributions to the British Journal of Radiology. The Royal College of Radiologists awarded him the Knox Medal in 1974 for a masterly exposition of the behaviour of head and neck cancer entitled 'The oncology of breathing and swallowing.' The section of laryngology of the Royal Society of Medicine awarded him the Harrison Prize in 1976 for his outstanding contributions to the management of head and neck cancer. His professional standing was acknowledged by his election as president of the Section of Radiology of the Royal Society of Medicine in 1967, of the Section of Oncology in 1972, and of the Association of Head and Neck Oncologists of Great Britain in 1974. His generosity was shown by his endowing the Leah Lederman lecture at the Royal Society of Medicine in memory of his mother, and in his presenting the furnishings for the council chamber of the Royal College of Radiologists.

Dr Lederman was a splendid host. Many of his friends and colleagues and visiting doctors from abroad have enjoyed his warm hospitality at his home in Montpelier Square. He was a lover of art, and his home contained a magnificent collection of paintings. He will be sadly missed in the spheres of both radiotherapy and ophthalmology. Our sympathy is extended to his wife Vera, who was his professional colleague for many years.

JMH

\section{Book review}

Color and Fluorescein Angiographic Atlas of Retinal
Vascular Disorders. By DAVID ORTH. Pp. 411. $£ 160 \cdot 00$. Williams and Wilkins: London. 1984.

This is a very well illustrated, comprehensive colour atlas of retinal vascular disease. There are accompanying fluorescein angiograms of high quality and, in appropriate sections, some excellent coloured diagrams explaining the pathogenesis of the various vascular conditions. Many of the photographs are accompanied by short clinical descriptions, which I found useful. However, there was little prognostic forecasting or follow-up data given. There is quite a lot of reduplication of the same retinal vascular conditions, and this, I think, makes the book too long. Its price puts it out of the reach of the majority of ophthalmologists, and not many ophthalmic libraries could afford to invest in it.

RONALD J MARSH

\section{Correction}

In the paper by W E Gillies and Anne Hughes entitled Results in 50 cases of strabismus after graduated surgery designed by A scan ultrasonography $(\mathrm{Br} J$ Ophthalmol $1984 ; 68: 790-5$ ) an error occurred on p. 794 , last paragraph. The second sentence should read: 'We prefer to avoid recessions greater than 0.2 of muscle length ...' (not $0.2 \mathrm{~mm}$ as printed). The 0.2 refers to a decimal estimate of muscle length such as is used in estimating cupping of the optic disc. 